\title{
A política educacional e o ensino remoto na educação infantil em Fortaleza em época de pandemia: relato de experiência
}

\author{
Educational policy and remote education in early childhood education in Fortaleza during \\ pandemic time: experience report \\ Política educativa y educación a distancia en la educación infantil en Fortaleza durante la \\ pandemia: informe de experiencia
}

Recebido: 26/10/2021 | Revisado: 05/11/2021 | Aceito: 24/11/2021 | Publicado: 06/12/2021

\author{
Gilzélia Cristina Pereira de Mendonça \\ ORCID: https://orcid.org/0000-0002-9636-5789 \\ Prefeitura Municipal de Fortaleza, Brasil \\ E-mail: gilzeliacristina@gmail.com \\ Gabriel Coutinho Gonçalves \\ ORCID: https://orcid.org/0000-0002-5960-2976 \\ Universidade Estadual do Ceará, Brasil \\ E-mail: fisiogabrielcoutinho@gmail.com \\ Dennys Ramon de Melo Fernandes Almeida \\ ORCID: https://orcid.org/0000-0002-4686-4379 \\ Universidade Federal do Rio Grande do Norte, Brasil \\ E-mail: dennysfernandes@ymail.com
}

\begin{abstract}
Resumo
O ano de 2020 surpreendeu o mundo pela força tempestuosa da pandemia da Covid-19. Em meados de março do corrente ano, o novo coronavírus chega ao Brasil e toda a dinâmica da vida em sociedade passa por grandes e necessárias mudanças, adotando novas formas de ser e estar no mundo. O país vem, ao longo desse período, enfrentando diversos problemas de ordem social, política, econômica e cultural, gerando consequências complexas, principalmente em assegurar o direito subjetivo à educação pública de qualidade, como expressa o artigo $5^{\circ}$ da Lei de Diretrizes e Bases da Educação Nacional (LDB), Lei n. ${ }^{\circ}$ 9.394/1996. Nossa proposta é apresentar um relato de experiência sobre o ensino remoto na educação infantil em Fortaleza no ano de 2020, abordando os desafios e as conquistas da política educacional em período de pandemia. A primeira etapa da educação básica, segundo determina o artigo 29 da LDB, define que a educação infantil tem por foco o desenvolvimento integral da criança de até cinco anos, em seus aspectos físico, psicológico, intelectual e social, complementando a ação da família e da comunidade. $\mathrm{O}$ relato de experiência elegeu destacar as ações que foram realizadas nessa etapa de ensino da rede municipal de Fortaleza, no período de isolamento social referente ao ano de 2020.
\end{abstract}

Palavras-chave: Educação; Pandemia; COVID-19; Desafios educacionais.

\begin{abstract}
The year 2020 surprised the world by the force and stormy Pandemic of Covid-19. In mid-March this year, the Coronavirus arrives in Brazil and the whole dynamic of life in society goes through great and necessary changes, adopting new ways of being and being in the world. The country has been facing several social, political, economic and cultural problems during this period, generating complex consequences, mainly in ensuring the subjective right to quality public education, as expressed in article 5 of the Law of Guidelines and Bases of National Education (LDBEN) 9,394 / 1996. Our proposal is to present an experience report on the remote education of early childhood education in Fortaleza in 2020, addressing the challenges and achievements of educational policy in a pandemic period. The first stage of basic education, as determined by article 29 of LDBEN 9.394 / 1996, defines that early childhood education focuses on the integral development of children up to 5 (five) years old, in its physical, psychological, intellectual and social aspects, complementing the action of the family and the community. The experience report chose to highlight the actions that were carried out in early childhood education in the municipal network of Fortaleza, in the period of social isolation, referring to the year 2020.
\end{abstract}

Keywords: Education; Pandemic; COVID-19; Challenges.

\section{Resumen}

El año 2020 asombró al mundo con la fuerza y la tormentosa Pandemia de Covid-19. A mediados de marzo de este año llega el Coronavirus a Brasil y toda la dinámica de la vida en sociedad sufre cambios importantes y necesarios, adoptando nuevas formas de ser y estar en el mundo. A lo largo de este período, el país ha venido enfrentando diversos 
problemas sociales, políticos, económicos y culturales, generando consecuencias complejas, principalmente en la garantía del derecho subjetivo a una educación pública de calidad, tal como se expresa en el artículo 5 de la Ley de Lineamientos y Bases de la Educación Nacional (LDBEN) 9.394 / 1996. Nuestra propuesta es presentar un informe de experiencia sobre la enseñanza a distancia de la educación infantil en Fortaleza en 2020, abordando los desafíos y logros de la política educativa durante un período de pandemia. La primera etapa de la educación básica, según lo determina el artículo 29 de la LDBEN 9394/1996, define que la educación infantil se enfoca en el desarrollo integral de los niños hasta los 5 (cinco) años, en sus aspectos físicos, psicológicos, intelectuales y sociales, complementando la acción de la familia y la comunidad. El relato de experiencia optó por destacar las acciones que se llevaron a cabo en educación infantil en la red municipal de Fortaleza, en el período de aislamiento social, referido al año 2020.

Palabras clave: Educación; Pandemia; COVID-19; Desafíos.

\section{Introdução}

O contexto de calamidade pública vivenciado pela população de Fortaleza desde março de 2020 para o enfrentamento da contaminação humana do novo coronavírus vitimou, até a presente data, precisamente 23 de dezembro de 2020 , segundo dados do Portal Integra Sus do Governo do Estado do Ceará, um total de 9.952 pessoas no estado, dentre as quais 6.187 somente cidade de Fortaleza. Esse fato exigiu dos parlamentares, casas públicas e comunidade científica medidas sanitárias urgentes, como forma de conter o alto índice de contaminação que vem assolando o mundo inteiro com drásticas e irreversíveis consequências. As principais medidas adotadas foram: o isolamento social, os cuidados básicos com a higiene e uso de máscaras para evitar a veiculação do vírus e mitigar o alto índice de letalidade. O contexto social precisou ser redimensionando para uma nova dinâmica de interação e convívio público. No campo educacional, a principal medida foi a suspensão imediata das aulas presenciais nas escolas, creches e centros de educação infantil (CEI) na capital cearense.

O Decreto Estadual n. ${ }^{\circ}$ 33.510, de 16 de março de 2020 (Ceará, 2020a), e o Decreto Municipal n. ${ }^{\circ} 14.611$, de 17 de março de 2020 (Fortaleza, 2020a), vêm determinar as medidas emergenciais para o enfrentamento da pandemia, com objetivo de conter a infecção humana e preservar as vidas da população fortalezense. O documento esclarece e adota critérios com medidas restritivas de cunho social, político, econômico e cultural. O inciso III do artigo $3^{\circ}$ do referido decreto municipal dispõe sobre a suspensão imediata das atividades educacionais em todas as unidades da rede pública municipal. O decreto teve data-fim em 31 de março de 2020, mas o contexto de saúde pública continuou se agravando e o poder público estadual e municipal publicaram novos decretos dando continuidade ao isolamento social como condição básica de combate, prevenção e enfrentamento de contágio do novo coronavírus.

A educação pública, como política macro de serviços essenciais, não poderia deixar de suprir o atendimento à comunidade, mesmo que de forma não presencial. Exigindo do poder público ações urgentes para planejar, estudar e executar novos formatos com o propósito de manter ativa as políticas educacionais e assegurar às crianças, jovens e adultos o direito subjetivo à educação determinado pela legislação nacional.

\section{Relato de experiência}

\section{a) O ensino remoto na educação infantil em Fortaleza}

O presente relato de experiência fez um recorte da realização do ensino remoto na etapa da educação infantil, no período de março a dezembro de 2020, em Fortaleza. A Secretaria Municipal de Fortaleza (SME), por meio da Coordenadoria de Educação Infantil (COEI), organizou um documento com as diretrizes do funcionamento remoto nas instituições de educação infantil (creches, CEIs e escolas) do município de Fortaleza. As orientações abordaram as especificidades da proposta curricular da educação infantil, apresentando estratégias exequíveis para preservar o diálogo e a parceria da instituição escolar com as famílias, com foco no fortalecimento de vínculos, para assegurar o "[...] desenvolvimento integral dos bebês e crianças por meio das interações e brincadeiras" (Sme/Coei, 2020), eixos estruturantes do trabalho pedagógico da educação infantil, segundo determinam as Diretrizes Curriculares Nacionais da Educação Infantil (DCNEI) (Brasil, 2009). 
A primeira etapa da educação básica é organizada em creches para atender as crianças de 0 a 3 anos e pré-escola, de matrícula obrigatória, conforme determina a Lei n. ${ }^{\circ}$ 12.795/2013, para as crianças de 4 e 5 anos. As instituições de educação infantil são espaços institucionais, não familiar, com o objetivo de "cuidar e educar" crianças de 0 a 5 anos. O "cuidar e o educar" são ações indissociáveis contidas no artigo $8^{\circ}$, inciso I, da Resolução n. ${ }^{\circ}$ 05/2009, que busca garantir os direitos básicos às crianças, tais como: “[...] proteção, saúde, liberdade, confiança, respeito, dignidade, brincadeira, convivência e interação com outras crianças" (Brasil, 2009).

$\mathrm{O}$ artigo $3^{\circ}$ da mesma resolução determina que o currículo na educação infantil é definido por “[...] um conjunto de práticas que buscam articular as experiências e os saberes das crianças com os conhecimentos que fazem parte do patrimônio cultural" (Brasil, 2009). A proposta curricular da educação mantém articulação com as diretrizes nacionais da educação básica e com a Base Nacional Comum Curricular (BNCC) (Brasil, 2018), na qual são determinados os princípios, fundamentos e procedimentos da política educacional, etapa educação infantil.

A criança é considerada "sujeito histórico e de direitos", centro do fazer pedagógico e do planejamento, aprende com as interações, experiências e vivências, construindo sua “[...] identidade pessoal e coletiva, brinca, imagina, fantasia, deseja, aprende, observa, experimenta, narra, questiona e constrói sentidos sobre a natureza e a sociedade, sendo capaz de produzir cultura" (Brasil, 2009). A criança é considerada protagonista do seu processo de desenvolvimento e aprendizagem. As múltiplas linguagens permitem à criança ressignificar e compreender sua relação consigo, com o outro e com o mundo.

Os eixos norteadores educação infantil são as interações e as brincadeiras, expressos na DCNEI (Brasil, 2009). Com base neste documento, a COEI definiu as orientações do trabalho remoto nas instituições de ensino da rede pública municipal de Fortaleza, com ênfase em manter vivo o diálogo permanente com as famílias, buscando prover todo o apoio necessário para que as crianças e as famílias possam se sentir acolhidas, apoiadas e assistidas em período de plena calamidade pública.

O trabalho pedagógico teve como foco cuidar, educar e proteger as crianças. O documento norteador das ações pedagógicas elaborado pela Coordenadoria da Educação Infantil definiu os seguintes objetivos:

Colaborar com as famílias para vivenciarem com bebês e crianças, por meio das interações positivas, diferentes experiências que promovam o seu bem-estar proteção e desenvolvimento integral;

Incentivar a família a brincar, ler e ouvir histórias, experimentar movimentos com bebês e crianças, fomentando diferentes linguagens infantis;

Fortalecer o vínculo afetivo entre a família e a criança; (Sme/Coei/ 2020).

A SME, por meio da COEI, organizou um plano de ação para subsidiar a rotina domiciliar realizada pelas instituições de ensino com o acompanhamento técnico e pedagógico dos distritos de educação. Em março de 2020, sob as determinações do Decreto Municipal n. ${ }^{\circ} 14.611$ (Fortaleza, 2020a), foram realizadas algumas reuniões com os gestores escolares para melhor esclarecer a dinâmica do trabalho pedagógico não presencial. As ações pedagógicas foram organizadas por meio de interações, vivências e brincadeiras, seguindo as orientações da DCNEI (Brasil, 2009). O ensino remoto foi realizado por meio de aplicativos eletrônicos (WhatsApp e SMS, dentre outros). O WhatsApp foi o aplicativo escolhido pelas famílias e professores por ser mais acessível à maioria.

As principais ações consistiam em abrir as salas de aulas para organizar grupos com as famílias, utilizando as plataformas digitais para realização e envio semanal de vivências e interações propostas pelos professores, assistentes e auxiliares, com acompanhamento dos coordenadores pedagógicos, mediação das famílias e participação direta das crianças. Semanalmente, a SME, por meio da Coordenadoria de Educação Infantil, enviava um link para ser respondido pelos coordenadores pedagógicos, como forma de acompanhar e monitorar as ações do trabalho remoto. As informações eram pertinentes às interações e vivências realizadas durante a semana, bem como o número de famílias que estavam participando efetivamente do processo pedagógico proposto pelos docentes da rede pública. O esforço consistia em manter vivo o vínculo da 
família com a unidade escolar e garantir às crianças os direitos de aprendizagem assegurados na BNCC (Brasil, 2018), ainda que de forma remota.

\section{b) Reorganização do calendário escolar de 2020}

O Conselho Municipal de Educação publicou a Resolução n. ${ }^{\circ}$ 022/2020, em 02 de abril de 2020, apresentando uma reorganização do calendário escolar para o ano letivo de 2020, considerando “[...] o plano de contingências e adoção de medidas com o objetivo de reduzir os riscos de contágio e disseminação do coronavírus (COVID-19)" (Fortaleza, 2020b), e seguindo as orientações do Decreto Estadual n. 33.519 (CEARÁ, 2020b). e do Decreto Municipal n. ${ }^{\circ} 14.611$ (FORTALEZA, 2020a), que dispõe sobre a situação de emergência em saúde pública e determina as medidas para enfrentamento e contenção da infecção humana do coronavírus. Diante dos fatos, resolve que o cumprimento das 800 horas aulas presenciais do calendário letivo poderá ser organizado com atividades pedagógicas domiciliares. O documento apresenta algumas ações direcionadas aos gestores da rede pública e das instituições de ensino privado que ofertam educação infantil, a saber:

I - Desenvolver um trabalho colaborativo e de parceria entre escola e família, sob a coordenação dos órgãos e instituições responsáveis por cada Rede de Ensino, para garantir o processo de ensino e aprendizagem dos estudantes. II - Orientar que as famílias acompanhem os estudantes em sua rotina de estudos. III - Apoiar e incentivar os docentes, na reorganização das ações pedagógicas e administrativas a serem desenvolvidas durante o período em que as aulas presenciais estiverem suspensas, com o objetivo de viabilizar material de estudo e aprendizagem de fácil acesso, divulgação e compreensão por parte dos estudantes e familiares por diversos meios eletrônicos, digitais e impressos, se necessário. IV - Incentivar aos estudantes que elaborem seu Diário de Estudos visando a sistematização de seu cronograma de estudos e o registro da sua rotina de estudos domiciliares, o que deverá ser acompanhado pelo professor. Continuação da Resolução CME N 022/2020 V - Reprogramar, ao final deste período, com a Comunidade Escolar, a reposição das atividades curriculares. VI - Registrar no planejamento das instituições de ensino, para fins de cumprimento da carga horária mínima anual prevista pela LDB, a carga horária de cada atividade a ser realizada pelos estudantes na forma não presencial. VII - Orientar aos docentes que registrem as atividades com as respectivas cargas horárias em seus Diários de Classe. VIII - Instruir os estudantes e as famílias sobre as ações de prevenção e higiene que todos devem praticar no combate ao coronavírus (Fortaleza, 2020a).

As recomendações da Resolução n. ${ }^{o}$ 002/2020 (Fotaleza, 2020b) subsidiaram o documento da SME (Fortaleza, 2020a), que dispõe sobre as “Orientações para o trabalho pedagógico domiciliar durante a suspensão das aulas presenciais”. Importante ressaltar que a legislação não autoriza a modalidade de educação a distância na educação infantil, ou seja, não há exigência de “desempenho acadêmico às crianças nessa faixa etária”. As especificidades da educação infantil dão destaque às dimensões lúdicas, afetivas e socioemocionais.

O Parecer n. ${ }^{\circ}$ 022/2020 (Fortaleza, 2020b) “[...] orienta sobre a reorganização e cumprimento do Calendário Letivo do ano de 2020 no Sistema Municipal de Ensino de Fortaleza, observando as medidas de prevenção e combate ao contágio do coronavírus (COVID-19)". Estabelece em seu artigo $4^{\circ}$ as diretrizes para a etapa da educação infantil, respeitando as especificidades e necessidades das crianças em seus processos de desenvolvimento e aprendizagem, a saber:

I - Respeito à legislação, que não autoriza o uso da modalidade de EAD para esta etapa, não devendo ser ofertadas atividades complementares, ou substitutivas, nessa modalidade, considerando que não há imposição de desempenho acadêmico para as crianças nesta faixa etária. II - Incentivo às famílias para, na medida do possível, desenvolverem vivências e experiências que garantam aprendizagem e desenvolvimento das crianças. III - Produção de campanhas televisivas e materiais orientadores às famílias para a realização de atividades interacionais e lúdicas na perspectiva do desenvolvimento e fortalecimento das dimensões afetiva e socioemocionais. IV - Observância aos princípios da Base Nacional Comum Curricular para Educação Infantil a fỉm de garantir a vivência de experimentos pelas crianças, com mediação dos professores, quando do retorno das atividades regulares presenciais. (Fortaleza, 2020b).

Diante do exposto, a rotina domiciliar priorizou manter um diálogo permanente com a comunidade e assistir as crianças no processo de desenvolvimento integral, garantindo os direitos de aprendizagem (conviver, explorar, participar, expressa-se, 
conhecer-se e brincar) estabelecidos pela BNCC (Brasil, 2018). O planejamento coletivo das aulas foi orientado e acompanhado pelos coordenadores pedagógicos para dar subsídios à elaboração das aulas, em áudios e vídeos, veiculadas por meio de mídias digitais. As interações, vivências e brincadeiras eram envidas pelos professores por três dias semanais, recebendo e devolvendo feedbacks às famílias como forma de dar continuidade e retorno ao trabalho pedagógico.

Importante salientar que antes de serem enviadas às famílias, as vivências e interações propostas pelos professores, auxiliares e assistentes educacionais eram validadas pelos técnicos formadores dos distritos. Os registros do planejamento e das aulas passaram a ser realizados de forma editável em arquivos de Word, anexados nos diários de classe sob a orientação dos coordenadores pedagógicos. Outra opção dada aos docentes era a realização dos registros de aula no próprio diário de classe. A COEI elaborou um documento com as orientações sobre a frequência das crianças que consistia no preenchimento de uma tabela mensal que identificava as semanas, o quantitativo de vivências/interações e o número de famílias interagindo nos grupos de trabalho.

O principal desafio encontrado consistia em manter contato com todas as famílias, sabendo que um percentual considerável dos pais não tinha aparelho celular e nem acesso à internet, fator que inviabilizava as ações pedagógicas. Outro fator relevante era que se apresentava um cenário em que alguns professores não tinham conhecimento sobre como trabalhar com as mídias digitais. Todos tiveram que vencer as dificuldades, com o imperativo de aprender, reinventar e reconstruir novos processos de ensino, para tornar possível a proposta de ensino remoto na rede pública municipal de Fortaleza.

A inclusão digital se fez imprescindível para que os atores do processo de ensino e aprendizagem realizassem suas funções pedagógicas, tanto os provedores, constituídos por uma equipe técnica de gestores, docentes e colaboradores, como pelas famílias, que precisariam ter aparelho de celular e dados móveis, principais insumos para receber e manter uma interlocução com a unidade escolar de forma periódica e sistemática, na qual denominamos de "rotina domiciliar".

A COEI elaborou um documento com um plano de ação que organizava as atribuições específicas para todos os segmentos da educação básica: núcleo gestor, professores e técnicos dos distritos de educação responsáveis por acompanhar toda a realização do trabalho pedagógico. A rotina domiciliar contemplava os momentos de alimentação, sono, descanso, higiene, interações e brincadeiras, como forma de melhor apoiar e orientar as famílias a manterem uma rotina pedagógica para cuidar, educar e proteger as crianças, segundo determinam as DCNEI (Brasil, 2009).

Com o objetivo de acompanhar as ações da rotina domiciliar, a SME/COEI criou um instrumental de Acompanhamento às interações com as famílias, contendo dados sobre o número de interações/vivências enviadas pelos professores, os feedbacks dos docentes às famílias e o número de famílias interagindo nos grupos de WhatsApp, com periodicidade semanal.

O monitoramento era realizado pelos distritos de educação, o qual teve início na $1^{\text {a }}$ semana no mês de março de 2020 , período que iniciou a suspensão das aulas presenciais, com encerramento na $35^{\mathrm{a}}$ semana em dezembro do mesmo ano. A instituição enviava os dados via link eletrônico e os distritos faziam análise e monitoramento dos dados para, em seguida, enviar à COEI, que, por sua vez, tabulavam os dados gerais gerando um relatório quantitativo e qualitativo no qual expressava a dimensão da proposta pedagógica possível e realizada no período, mesmo que apresentasse desalinhos de altos e baixos.

O universo de experiências, conhecimentos e habilidades dessas crianças, diversificando e consolidando novas aprendizagens, atuando de maneira complementar à educação familiar - especialmente quando se trata da educação dos bebês e das crianças bem pequenas, que envolve aprendizagens muito próximas aos dois contextos (familiar e escolar), como a socialização, a autonomia e a comunicação (Brasil, 2018, p. 34).

\section{c) Material pedagógico}

O material pedagógico utilizado pelas crianças da pré-escola no período foi o livro da família "Amor, cuidado e educação" e o livro didático "Entrelinhas para você", da editora OPET/SEFE. Ambos representaram uma ferramenta didática de apoio ao trabalho da rotina domiciliar. Outra opção apresentada à equipe docente foi o aplicativo "Aprender Mais”, da Secretaria 
da Educação do Estado do Ceará (SEDUC). O material de audiovisual constava de uma série de vídeos educativos veiculados mensalmente por plataformas eletrônicas e emissoras de TV educativas. Apresentava temáticas específicas corroborando para o fortalecimento de vínculos das famílias com as instituições de ensino e, ao mesmo tempo, fortalecendo e ampliando as ações para promover o processo de desenvolvimento e aprendizagem das crianças.

O Decreto n. ${ }^{\circ} 14.651$ (Fortaleza, 2020c), de 19 de abril de 2020, determinou a continuação do isolamento social em combate ao enfrentamento da pandemia da Covid-19, estabelecendo medidas restritivas ao funcionamento de vários setores da economia, eventos culturais, esportivos e escolas. O distanciamento social, a obrigatoriedade do uso de máscaras e os cuidados básicos de higiene foram indicados como ações preventivas para evitar a contaminação humana pelo novo coronavírus e minimizar as drásticas consequências à população.

Em agosto, foi publicado o Decreto n. 14.769 (Fortaleza, 2020d), de 16 de agosto de 2020, sinaliza uma leve abertura de funcionamento para algumas atividades de âmbito social, educacional e econômico, de forma escalonada e faseada, cumprindo uma fase de transição, mas o sistema público de ensino da rede municipal de Fortaleza, opta por permanecer no regime remoto.

\section{d) A formação continuada de professores}

A permanência das aulas remotas instituiu o trabalho home office para alguns setores do sistema municipal de educação, fortalecendo o trabalho da rotina domiciliar, que, aos poucos, ganhava corpo e introduzia uma nova dinâmica ao processo educacional. A formação continuada foi retomada assumindo um formato de aulas a distância (EAD), com a utilização das mídias digitais. Com periodicidade mensal, foram ministradas pelos técnicos formadores dos distritos, sob a coordenação da SME/COEI e pelos coordenadores pedagógicos, quando a formação ocorria no contexto educacional por meio virtual.

A COEI realizava reuniões periódicas com as gerentes da educação infantil dos distritos para discutir sobre a organização, o envolvimento e o feedback do processo implementado por meio da rotina domiciliar. Um fato significativo e complexo que envolve o trabalho remoto se reporta à compreensão dos educadores com o fato de que os pais, não sendo pedagogos, encontrariam dificuldades em desenvolver com as crianças as interações e as vivências propostas. Contudo, foi percebido um esforço grandioso das famílias em procurar responder e dar as devolutivas das propostas enviadas pelos professores.

A parceria escola-família evidenciou ganhos significativos nunca antes conquistados, principalmente no que se refere à frequência e à participação das crianças nas vivências e interações da rotina domiciliar. Outro fator de extrema importância foi o de possibilitar que as famílias tivessem a oportunidade de conhecer o currículo da educação infantil e o trabalho pedagógico realizado pelos professores, desmistificando alguns equívocos conceituais sobre a educação infantil.

A formação continuada de professores e coordenadores pedagógicos teve por objetivo subsidiar a ação pedagógica na interação entre coordenadores, professores, assistentes e auxiliares com as famílias. Teve início no mês de janeiro de 2020, sendo realizado o encontro pedagógico, que teve como tema "O Projeto Político Pedagógico: instrumento para uma gestão escolar democrática", realizado no contexto escolar com carga horária de 8 horas aulas e ministrado pelos coordenadores pedagógicos. Em março, a formação aconteceria nos polos de formação, mas a pandemia da Covid-19 exigiu isolamento social a favor de restringir a contaminação humana pelo novo coronavírus.

Por determinação do Decreto n. ${ }^{\circ} 14.611$ (Fortaleza, 2020a), a ação foi cancelada, sendo retomada em junho, de forma virtual, em salas de aula síncronas, com a temática "A importância da escuta e dos registros no contexto do isolamento social”. A intenção se reportou em resgatar o trabalho realizado em 2019, cuja temática se centrava na "Documentação pedagógica" que envolve um olhar e um fazer pedagógicos com base na reflexão dos educadores a partir dos registros e documentos produzidos e obtidos na rotina pedagógica da educação infantil, tais como: planejamento, observação, registro, reflexão e avaliação. 
Segundo Proença (2018), a documentação pedagógica é uma abordagem que considera a cultura das infâncias e concebe a criança como ser potente, capaz e “[...] protagonista de suas investigações para conhecer e apropria-se da cultura à qual pertence". A ação pedagógica é realizada “com a criança” e não "para a criança”. A citação a seguir exemplifica com clareza o papel da formação de professores como uma ação integradora, questionadora e reflexiva que mantém diálogo constante com seus pares e com as famílias para a realização do processo de desenvolvimento e aprendizagem das crianças de forma significativa e compartilhada.

A formação de professores segundo essa concepção é vista como uma busca coletiva e permanente de possibilidades, escolhas, pesquisas e desafios, a fim de enriquecer o ambiente escolar. Dessa forma experiências podem acontecer de maneira cada vez mais enriquecedoras, tanta para as crianças e suas famílias quanto para os adultos, integrando o espaço da instituição ao seu entorno, formando uma comunidade educativa e uma cultura de grupo (Proença, 2018, p. 9).

Dada a complexidade do ano atípico de 2020, o calendário escolar sofreu algumas mudanças, as férias dos professores foram em agosto. O segundo semestre letivo começou com um encontro pedagógico trazendo a perspectiva do "Autocuidado: o cuidado de si para o cuidado do outro", tema pertinente ao contexto vivido por todos para o enfrentamento da pandemia que destruiu planos, projetos e vidas.

Em setembro, o tema abordado enfatizava "O uso da tecnologia para construção de novas aprendizagens", com encontro formativo por meio do Google Meet e Google Sala de Aula. O estudo passaria a ser complementado com leituras de textos do Documento Referencial Curricular do Estado do Ceará (DCRC) (Ceará, 2019) e relatos escritos a partir dos questionamentos propostos das temáticas discutidas na formação, com postagem em plataformas digitais no Google Sala de Aula. A formação assumiu um formato híbrido, com encontros virtuais no Google Meet e atividades a distância, que foram organizadas em dois módulos específicos com uma carga horária de 16 horas, ministrada e acompanhada pelos técnicos dos distritos de educação.

O percurso formativo foi concluído com uma consulta pública sobre o "Documento Preliminar da Proposta Curricular para Educação Infantil”. A proposta curricular da educação infantil data de 2016, período que antecede a publicação da BNCC (Brasil, 2018), fato que exigiu revisitar e atualizar o documento. O movimento contou com a participação efetiva de toda a comunidade escolar, houve uma intensa mobilização das instituições de ensino, apresentando o documento e permitindo discussões e reflexões com os gestores, coordenadores, professores, auxiliares/assistentes e as famílias sobre a nova Proposta Curricular do Município de Fortaleza. O documento apresentava as diretrizes e orientações do trabalho pedagógico realizado em creches e escolas com os bebês, crianças bem pequenas e crianças pequenas na faixa etária de 1 a 5 anos.

Concomitante a formação continuada, a SME realizou alguns webinares educativos, e contou com as parcerias de outras instituições abordando temáticas específicas ao período vivenciado com o novo formato de ensino remoto, buscando dar suporte pedagógico ao trabalho realizado por coordenadores, professores, auxiliares e assistentes educacionais das unidades da rede pública de ensino de Fortaleza.

O primeiro webinar aconteceu no dia 14 de abril de 2020, com o tema "Como fica a educação infantil em meio à pandemia de Covida-19?”, veiculado pelo YouTube (youtube.com/jeduca), ação da Rede Nacional pela Primeira Infância. A "Série Boas Práticas" constituiu de uma ação que teve como objetivo divulgar as atividades exitosas de alunos e profissionais da rede realizadas na rotina domiciliar e dar visibilidade ao esforço dos profissionais da educação que tiveram que aprender a trabalhar com as mídias digitais. A palavra de ordem era se reinventar e elaborar uma nova forma de interagir com as crianças e suas famílias, assim como a superação das famílias que tiveram que responder ao desafio e à responsabilidade em mediar as vivências/interações propostas pelos professores a seus filhos.

A dinâmica do Projeto "Boas Práticas" consistia no envio por parte das instituições de ensino de registros por meio de vídeos, escritos e relatos de experiências da educação infantil e ensino fundamental à SME, que apreciava o material recebido e, em seguida, divulgava no site oficial. Em maio foi lançado o Projeto "Diálogos online", sala de aula virtual que promovia debates 
e discussões com os professores da rede sobre o fazer docente em época de pandemia. A ação era conduzida pelos professoresformadores da SME, abordando os temas sobre: alfabetização, leitura, competência socioemocional, letramento científico, ensino da história e da matemática. A troca de experiências entre docentes permitia dar visibilidade à superação dos desafios e às conquistas obtidas pelo trabalho remoto.

O Projeto "Ateliê Fortaleza 2040" faz parte de um planejamento estratégico de governo para planejar a cidade, garantindo cidadania e bem-estar da população. Constitui um plano de desenvolvimento de curto, médio e longo prazo com três linhas de atuação "Mestre Urbanístico, Mobilidade e Desenvolvimento Econômico e Social” (Fortaleza, 2019). O objetivo principal do plano é tornar a cidade mais "acessível, justa e acolhedora", visando estabelecer um modelo de gestão eficiente e comprometido com o crescimento econômico, social e cultural da cidade.

O Projeto “Ateliê Fortaleza 2040” foi lançado em um webinar da educação infantil com o tema "A arte de documentar: uma escola reflexiva". A palestra foi proferida pela doutora Maria Alice Proença, que abordou a importância da "Documentação Pedagógica" como ferramenta de registro e acompanhamento do processo pedagógico curricular vivido por crianças e profissionais da educação. Na ocasião, foi lançado o "Documento Projeto Ateliê: uma tessitura protagonizada pela triangulação família, escola e criança", corroborando com o plano de ação para a primeira infância a favor da política pela garantia dos direitos das crianças.

As ações de formação implementadas pela SME buscaram apoiar e dar consistência ao percurso formativo dos profissionais de educação, que tiveram grandes dilemas e desafios enfrentados no ano de 2020.

Em abril de 2020, o Decreto Municipal n. 14.634 (Fortaleza, 2020e) prorroga as medidas de enfrentamento à disseminação do novo coronavírus, permanecendo com a dinâmica de aulas remotas, período em que a SME lançou a Campanha “Educação para a Vida: Coronavírus Não!”, ação institucional que criou o prêmio "SME - O contexto de Isolamento social ao combate ao coronavírus". Intencionava potencializar o protagonismo juvenil, motivando os alunos da rede a uma reflexão e expressão artística sobre os sentimentos que envolviam o tema em pauta, buscando fortalecer o processo de aprendizagem com atividades domiciliares diversificadas.

Importante ressaltar que desde de março de 2020 a Prefeitura Municipal de Fortaleza (PMF) iniciou a entrega de kits de alimentação às famílias das crianças atendidas na rede, como forma de garantir segurança alimentar aos alunos no período do isolamento social e rotina domiciliar, sabendo que a alimentação é condição básica para manter o sistema imunológico fortalecido, buscando minimizar as situações de vulnerabilidade social em que estão inseridas as crianças e suas famílias. A ação foi bem recebida pela comunidade, que percebeu uma atenção do poder público para com as comunidades carentes, período em que Fortaleza e muitas capitais tiveram que entrar em lockdown para o enfrentamento e combate à contaminação humana da Covid-19. Em maio de 2020, com o Decreto n. 14.663 (Fortaleza, 2020f), foi instituída a política de isolamento social rígido como medida de enfrentamento à Covid-19 frente ao alarmante número de casos registrados na capital cearense.

\section{e) O processo de avalição da educação infantil}

Em novembro de 2020, o Conselho Municipal de Educação publicou o Parecer n. ${ }^{\circ}$ 087/2020 (Fortaleza, 2020g), em que dispõe sobre a continuidade das atividades pedagógicas remotas, o processo de avaliação da aprendizagem e a matrícula para o ano letivo de 2021. Importante salientar que o Parecer n. ${ }^{\circ}$ 05/2020 (Fortaleza, 2020h) orienta sobre a reorganização do calendário escolar e o cumprimento da carga horária mínima anual, em razão da pandemia da Covid-19, e a realização de atividades pedagógicas (interações/vivências) não presenciais organizadas sob uma rotina domiciliar que adotava como estratégias “momentos lúdicos, recreativos, criativos e interativos", envolvendo a tríade família, escola e criança. Segundo a legislação nacional, a avalição da educação infantil far-se-á mediante registros e relatórios, com o propósito de acompanhar o processo de desenvolvimento integral da criança, sem objetivo de promoção ou classificação para o ingresso no ensino fundamental. A 
promoção da criança para os agrupamentos seguintes ocorre de forma automática, respeitando a determinação do corte etário de 31 de março de 2021.

A SME/COEI organizou um documento para melhor orientar as instituições escolares sobre a realização dos relatórios semestrais, que foram realizados no período do fechamento do primeiro e segundo semestres, respectivamente nos meses de julho e dezembro/2020. Considerando as especificidades da educação infantil com o imperativo de adequação das ações pedagógicas interações/vivências não presenciais realizadas por meio de aplicativos em grupos de WhatsApp com as famílias; considerando a realidade de vulnerabilidade social que impediu a inserção de algumas famílias e crianças ao acesso a equipamentos celulares e a rede internacional de comunicação (Internet), consistiu em um fato indicativo de trazer à realidade o fosso alarmante da desigualdade social premente no país. Diante de todas essas considerações expressas, a Coordenadoria de Educação Infantil decide por um relatório semestral que seja elaborado por turma de agrupamento de crianças.

Considerando que a documentação pedagógica é uma estratégia que possibilita a visualização da originalidade dos processos construtivos das crianças, de suas experiências individuais e em grupo e que a análise dos documentos, ao reunir fatos da rotina das crianças da Educação Infantil junto aos seus Coordenadoria da Educação Infantil e familiares, permite aos educadores revisitar as vivências/interações propostas (por meio dos aplicativos on-line), escutando e observando as famílias e crianças, a fim de compreender melhor as culturas infantis, como acontecem seus processos de aprendizagem e como constroem a leitura de mundo (Fortaleza, 2020i).

Segundo estabelece o documento da COEI, o relatório bimestral de avaliação da educação infantil deve conter "análises, reflexões e interpretações" do período vivido pelas crianças e suas famílias, expressos a partir dos registros de feedbacks das interações/vivências produzidos pelas crianças. A coordenação pedagógica da instituição organizou com a equipe de profissionais da educação infantil, professores, auxiliares e assistentes, um momento individual com cada família para a socialização dos relatórios, por meio de aplicativos eletrônicos, os mesmos utilizados nos grupos de sala de aula. O principal objetivo é manter um diálogo acolhedor e respeitoso, abordando a dinâmica da rotina domiciliar, permitindo uma escuta ativa da família e da criança, para reunir todas as evidências possíveis a favor de perceber a dinâmica encontrada pelos pais para superar os desafios e assegurar às crianças os direitos de aprendizagem (conviver, participar, expressa-se, brincar, explorar e conhecese), enunciados pela BNCC (Brasil, 2018). A ação revalida o compromisso da rede pública com o fortalecimento de vínculos entre a instituição escolar e a comunidade.

Em dezembro de 2020 foi publicado o Decreto 14.879 (Fortaleza, 2020j), prorrogando o isolamento social no município de Fortaleza. A COEI elaborou um documento para orientar o processo de transição das crianças da educação infantil, segmento creche, para o ingresso à pré-escola, e desta para o ensino fundamental, com ações pedagógicas que promovam "acolhimento e bem-estar" aos bebês e crianças pequenas. Dentre as ações propostas, vale destacar a criação de um vídeo institucional para apresentar às crianças e às famílias os espaços físicos da escola, grupo gestor e professores. A ação seguinte foi promover um encontro virtual entre os professores da educação infantil e ensino fundamental, com objetivo de esclarecer "[...] as especificidades da educação infantil como a construção da autonomia, o aguçamento da curiosidade, o uso de diferentes linguagens para expressar suas ideias, bem como a indissociabilidade entre o cuidar e o educar” (Sme/Coei, 2020j). Importante ressaltar que a escuta ativa das necessidades, interesses e curiosidades das crianças possibilitará um processo de transição mais tranquilo e seguro para o enfrentamento de uma nova realidade marcada por incertezas e inseguranças.

Sugiro que os trabalhos futuros com foco nessa mesma temática, possam apresentar a curto, médio e longo prazo, os impactos positivos e negativos advindos da expeiência inusitada e vivenciada por alunos, professores e gestores nos anos de 2020 e 2021, período em que a educação precisou se reinventar e reconstruir novas formas de ensinar e aprender. Que repercussões, consequências, desafios, possibilidades e ensinamentos a Pandemia da Covid-19, trouxe para sociedade do século $\mathrm{XXI}$ ? 


\section{Considerações Finais}

Dado o contexto situacional de enfrentamento à Covid-19, as autoridades científicas, sanitárias e políticas decidiram pela continuidade do isolamento social, e o ensino remoto perdurou por todo o ano letivo de 2020. Ainda que em alguns momentos houvesse amplas discussões de um possível retorno ao atendimento presencial, fato que fez a rede municipal realizar um plano de ação comtemplando adequações e reformas nos prédios escolares, além de aquisição de insumos e materiais (EPIs) para uma possível retomada ao ensino presencial. Contudo, o contexto social não permitiu que essa realidade fosse concretizada, e o ano letivo de 2020 foi concluído com a dinâmica da rotina domiciliar, caminhada de grandes desafios, descobertas, aprendizagens e conquistas de todos os profissionais que compõem a rede pública de ensino, dentre os quais destacamos os professores, assistentes e auxiliares educacionais, coordenadores pedagógicos, gestores escolares, técnicos dos distritos e da SME.

Ademais, vale ressaltar a importante e grandiosa contribuição das famílias no processo de aprendizagem e desenvolvimento das crianças, mesmo desconhecendo as teorias e técnicas pedagógicas, mediaram a rotina domiciliar com disposição e sensibilidade, sob a condução pedagógica dos professores da rede pública municipal de ensino. O fortalecimento de vínculos entre as famílias e a instituição escolar foi um fator relevante e determinante no período do isolamento social, buscando consolidar a relação efetiva e necessária da família com a escola a favor do processo de desenvolvimento integral e integrado da criança, propósito que conseguiu assegurar a permanência das crianças no ciclo de escolaridade, e assim evitar a evasão escolar, dado o quadro situacional do contexto de Pandemia.

O ano letivo atípico de 2020 impôs a todos diversos desafios a vencer, fortalecendo a importância da aprendizagem constante no processo de transformação e mudança, em que a sociedade precisou se adaptar para uma nova forma de ver, sentir e viver no mundo. A reconstrução, reestruturação e reinvenção associadas às tecnologias e às mídias sociais foram ferramentas básicas e necessárias para superar algo nunca visto nem vivido no século atual.

\section{Referências}

Brasil. (1996). Ministério da Educação. Lei n. 9.394, de 20 de dezembro de 1996. Estabelece as diretrizes e bases da educação nacional. MEC/CNE.

Brasil. (2009). Ministério da Educação. Conselho Nacional de Educação. Resolução n. 05, de 17 de dezembro de 2009. Fixa as Diretrizes Curriculares Nacionais para Educação Infantil. MEC/CNE/CEB.

Brasil. (2018). Ministério da Educação. Base Nacional Comum Curricular: educação é a base. MEC.

Brasil. (2020). Ministério da Educação. Conselho Nacional de Educação. Parecer n. 005/2020. Dispõe sobre a reorganização do calendário escolar e sobre a possibilidade de cômputo de atividades pedagógicas não presenciais para fins de cumprimento da carga horária mínima anual, em razão da pandemia da Covid19. Brasília: MEC.

Ceará. (2019). Documento Referencial Curricular do Estado do Ceará. Governo do Estado do Ceará: Seduc.

Ceará. (2020a). Decreto n. 33. 510 de 16 de março de 2020. Decreta a situação de emergência em saúde e dispõe sobre medidas para o enfrentamento e contenção da infecção humana pelo novo Coronavírus. Diário Oficial do Estado do Ceará. Governo do Estado do Ceará: Seduc.

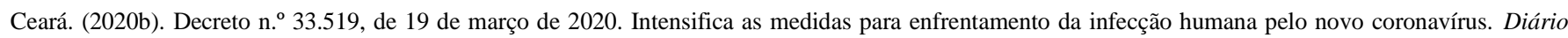
Oficial do Estado do Ceará, ano XII, n. ${ }^{\circ}$ 56, série 3, p. 1-3.

Fortaleza. (2020a). Decreto n. ${ }^{\circ} 14.611$, de 17 de março de 2020. Decreta a situação de emergência em saúde e dispõe sobre medidas para o enfrentamento e contenção da infecção humana pelo novo Coronavírus. Diário Oficial do Município de Fortaleza, ano LVX, n. 16.711, p. 1-2.

Fortaleza. (2020b). Resolução CME n. ${ }^{\circ}$ 022/2020, de 2 de abril de 2020. Orienta sobre a reorganização e cumprimento do Calendário Letivo do ano de 2020 no Sistema Municipal de Ensino de Fortaleza, observando as medidas de prevenção e combate ao contágio do coronavírus (COVID-19). Fortaleza: SME.

Fortaleza. (2020c). Decreto n. ${ }^{\circ}$ 14.651, de 19 de abril de 2020. Estabelece medidas complementares de enfrentamento da COVID-19, no âmbito do Município de Fortaleza, e dá outras providências. Diário Oficial do Município de Fortaleza, ano LVX, n. 16.734, p. 1-2.

Fortaleza. (2020d). Decreto n. ${ }^{\circ} 14.769$, de 16 de agosto de 2020. Prorroga o isolamento social no município de fortaleza e dá outras providências. Diário Oficial do Município de Fortaleza, ano LVX, n. 16.827, p. 1-2.

Fortaleza. (2020e). Decreto n. 14.634, de 05 de abril de 2020. Prorroga as medidas de enfrentamento à disseminação do Novo Coronavírus no Estado do Ceará, e dá outras providências. Diário Oficial do Município de Fortaleza, ano LVX, n. 16.724, p. 1-2. 
Research, Society and Development, v. 10, n. 16, e49101622362, 2021

(CC BY 4.0) | ISSN 2525-3409 | DOI: http://dx.doi.org/10.33448/rsd-v10i16.22362

Fortaleza. (2020f). Decreto n. 14.663, de 05 de maio de 2020. Institui, no Município de Fortaleza, a Política de Isolamento Social Rígido como Medida de enfrentamento à COVID - 19, e dá outras providências. Diário Oficial do Município de Fortaleza, ano LVX, 16.744, 1-3.

Fortaleza. (2020g). Parecer $n .^{\circ} 87 / 2020$. Orienta sobre a continuidade das atividades pedagógicas não presenciais com vistas ao cumprimento do calendário letivo de 2020. Conselho Municipal de Educação: SME.

Fortaleza. (2020h). Parecer n..$^{\circ}$ 0205/2020. Orienta sobre a reorganização do Calendário Escolar e o cumprimento da carga horária mínima anual, em razão da Pandemia da COVID-19. Conselho Municipal de Educação: SME.

Fortaleza. (2020i). Prefeitura Municipal de Fortaleza. Relatório do Plano Fortaleza 2040: 2017-2020 / Prefeitura Municipal de Fortaleza - Fortaleza 2020: IPLANFOR.

Fortaleza. (2020j). Decreto n. 14.879, de 20 de dezembro de 2020. Altera o Decreto n. ${ }^{\circ}$ 14.875, de 12 de dezembro de 2020. Diário Oficial do Município de Fortaleza, ano LVX, n. 16.931, p. 1-3.

Fortaleza. (20201). SME/COEI. Orientações para o Processo de Transição da Criança da Educação Infantil para o Ensino Fundamental. SME.

Proença, M. A. (2018). Prática docente: a abordagem de Reggio Emília e o trabalho com projetos, portfólios e redes formativas. Panda Educação. 